\title{
Management of Multivessel Coronary Disease in ST-segment Elevation Myocardial Infarction
}

\author{
Amerjeet S. Banning ${ }^{1}$ Anthony H. Gershlick ${ }^{1,2}$
}

Published online: 4 August 2015

(C) The Author(s) 2015. This article is published with open access at Springerlink.com

\begin{abstract}
Primary PCI of infarct-related arteries is the preferred reperfusion strategy in patients presenting with STsegment elevation myocardial infarction (STEMI). Up to $40 \%$ of such patients demonstrate evidence of multivessel, non-infarct-related artery coronary disease. Previous nonrandomised observational studies and their associated meta-analyses have suggested that in such cases only the culprit infarct-related artery (IRA) lesion should be treated. However, recent randomised controlled trials have demonstrated improved clinical outcomes with lower major adverse cardiovascular events (MACE) rates when complete revascularisation is undertaken either at index primary percutaneous coronary intervention (PPCI) or during index admission. These trials suggest that current guidelines pertaining to treatment of non-infarct-related artery $(\mathrm{N}$ IRA) lesions in STEMI patients with multivessel disease may need to be reconsidered depending on future trials. However, issues remain around timing of N-IRA intervention, the use of fractional flow reserve (FFR) or intravascular imaging to guide intervention in N-IRA lesions and the need to demonstrate reductions in hard clinical endpoints (death and MI) after complete revascularisation;
\end{abstract}

This article is part of the Topical Collection on Management of Acute Coronary Syndromes

Amerjeet S. Banning

ab758@le.ac.uk

Anthony H. Gershlick

agershlick@aol.com

1 Department of Cardiovascular Sciences, University of Leicester Glenfield Hospital, Groby Road, Leicester LE3 9QP, UK

2 Department of Cardiology, University Hospitals of Leicester NHS Trust Glenfield Hospital, Groby Road, Leicester LE3 9QP, UK these issues will need to be addressed through future trials. Clinicians must judge on the currently available data, whether it is still safer to leave important stenosis in $\mathrm{N}$ IRA untreated.

Keywords Myocardial infarction · Primary PCI $\cdot$ Multivessel disease $\cdot$ Complete revascularisation $\cdot$ Non-infarct-related artery $\cdot$ Revascularisation strategy

\section{Introduction}

Primary percutaneous coronary intervention (PPCI) is the preferred reperfusion strategy in ST-segment elevation myocardial infarction (STEMI). It is estimated that $40 \%$ of patients who present with STEMI have multivessel disease at index angiography [1-4]. How such significant lesions in the non-infarct-related vessels should be treated is controversial. There is evidence to suggest such patients have worse long-term outcomes compared to patients presenting with single-vessel disease, including a need for repeat revascularisation and repeat admissions with MI $[5,6]$. However, undertaking PCI in by-stander lesions during STEMI can have potential complications. Current guidelines from the ACC/AHA [7] and ESC [8] recommend treatment of the culprit artery only in the absence of haemodynamic compromise.

The aim of this article is to review the current data pertaining to management of non-culprit lesions in patients presenting with ST elevation myocardial infarction, as well as some of the current guideline recommendations and the remaining outstanding questions regarding management of these lesions. 


\section{Non-Randomised Studies and Current Guideline Recommendations}

Much of the initial evidence base pertaining to complete revascularisation in STEMI patients with multivessel disease came from non-randomised observational cohort studies and registry data (Table 1; 9-19, 21-24). These observational studies contain some potential confounding factors, such as cardiogenic shock within the groups treated with complete revascularisation that may influence the outcome measures [24].

A meta-analysis of early observational and randomised studies [25•] showed benefit in longer-term mortality with complete revascularisation if non-infarct-related artery $(\mathrm{N}$ IRA) PCI is performed on a staged basis as opposed to being undertaken the time of the index PCI.

A separate meta-analysis by Bangalore et al. included 19 studies (2 randomised studies, 17 observational or registry studies) to evaluate early ( $<30$ days) and long-term safety and efficacy of multivessel PCI [26]. Of the 61,764 patients included, multivessel PCI was performed in only 9690 (16\%) of patients with the remaining $84 \%$ undergoing culprit lesion only PCI. Overall there was no significant difference in 30day mortality $(\mathrm{OR}=1.04,95 \% \mathrm{CI}=0.93-1.15)$; however, when stratified by timing of intervention, 30-day mortality was lower with the complete revascularisation when N-IRA PCI was performed as a staged procedure $(\mathrm{OR}=0.44,95 \%$ $\mathrm{CI}=0.33-0.59$ ), while there was a trend towards worse 30-day mortality if N-IRA PCI was performed at the same time as the culprit PPCI $(\mathrm{OR}=1.19,95 \% \mathrm{CI}=1.06-1.34)$. Longer-term mortality ( $>1$ year post-primary $\mathrm{PCI}$ ) was significantly lower with complete revascularisation $(\mathrm{OR}=0.67,95 \% \mathrm{CI}=0.58$ 0.79 ) and again, this effect was attenuated if complete revascularisation was undertaken at the same sitting as primary $\mathrm{PCI}$ of the culprit lesion $(\mathrm{OR}=0.91,95 \% \mathrm{CI}=0.73-1.14)$. A 30-day and longer-term major adverse cardiovascular event (MACE) was significantly lower with complete revascularisation regardless of when the N-IRA PCI was undertaken. There was a high degree of heterogeneity seen amongst the studies within this meta-analysis, particularly in those where complete revascularisation was undertaken at the same sitting.

A propensity-matched analysis of 3984 patients with STEMI and multivessel disease presenting in eight cardiac centres within London between 2004 and 2011 looked at outcomes from culprit-only and complete revascularisation at time of PPCI [27]. Cardiogenic shock and LMS disease was excluded from the analysis. In this cohort, 555 patients, i.e. $13.9 \%$ of patients with multivessel disease, underwent multivessel PCI. Although propensity-matched analysis suggested an improved survival with culprit-only PCI during the index procedure $(\mathrm{HR}=0.64 ; 95 \% \mathrm{CI}=0.45-0.90 ; P=0.010)$ and reduced MACE with culprit-only PCI (HR $=0.49 ; 95 \%$
$\mathrm{CI}=0.32-0.76 ; P=0.002)$, there are some important limitations to this study. Specifically, it could not be ascertained how many patients in the culprit-only cohort went on to have staged complete revascularisation. Secondly, presence of cardiogenic shock was based on use of inotropes and IABP in cases as no haemodynamic data were available, hence it is possible a proportion of the patients undergoing multivessel disease had early cardiogenic shock prior to receiving complete revascularisation.

The question has been raised as to the potential downsides of leaving a non-infarct-related artery untreated. In a retrospective analysis of 28,282 STEMI patients, it was shown that the presence of multivessel disease $(52.8 \%$ ) appeared to confer a worse prognosis, with the presence of N-IRA disease being significantly associated with 30-day mortality (unadjusted, 4.3 vs $1.7 \%$, respectively; risk difference, $2.7 \%[95 \% \mathrm{CI}=2.3-3.0 \%], P<.001$; and adjusted, $3.3 \mathrm{vs}$ $1.9 \%$, respectively; risk difference, $1.4 \%[95 \% \mathrm{CI}=1.0$ $1.8 \%$ ], $P<.001$ ) [28].

The 2012 ESC guidelines on STEMI management recommend "PCI should be limited to the culprit vessel with the exception of the presence of cardiogenic shock and persistent ischaemia after PCI of the supposed culprit lesion" (Class IIa recommendation, Level of evidence B) [7]. Prior to the publication of recent randomised studies, in 2013 the ACCF/AHA guidelines give PCI to an non-infarct-related artery at the time of primary PCI without haemodynamic instability a class III recommendation (Level of evidence B) [8]. These recommendations are largely drawn on the preceding non-randomised studies and meta-analyses as outlined above.

\section{Randomised Studies}

Two recently reported UK-based RCTs comparing culpritonly revascularisation to treatment of any trial-defined significant additional non-IRA in STEMI with multivessel disease have opened a debate as to how these patients might be managed.

PRAMI was a randomised open trial that recruited 465 patients over 4 years, who presenting with STEMI were found to have multivessel coronary disease [29••]. The study defined the presence of multivessel disease as a non-infarct-related artery (N-IRA) lesion $>50 \%$ stenosis within a major epicardial artery. Patients recruited to the study were randomised to receive either culprit-only PCI or PCI of both culprit and NIRA lesions at the same sitting (i.e. during index primary PCI procedure). The primary outcome measure was a composite of cardiovascular death, new MI and refractory angina defined as angina despite medical therapy supported by evidence of objective ischaemia The study was discontinued early by the DSMB at a mean follow-up of 23 months, due to a significant difference in primary endpoint in favour of complete 
Table 1 Summary of non-randomised studies comparing complete and culprit-only revascularisation in STEMI patients

\begin{tabular}{|c|c|}
\hline Study & Description \\
\hline $\begin{array}{l}\text { Abe et al. } 2012 \\
\text { [9] }\end{array}$ & $\begin{array}{l}\text { Retrospective cohort study. } 274 \text { STEMI } \\
\text { patients with multivessel disease } \\
\text { undergoing culprit-only PCI }(n=220) \text { or } \\
\text { multivessel PCI }(n=54) \text {. Median follow-up } \\
\text { of } 374 \text { days. }\end{array}$ \\
\hline $\begin{array}{c}\text { Cavender et al. } \\
\text { 2009. [10] }\end{array}$ & $\begin{array}{l}\text { Retrospective analysis of the NCDR database } \\
\text { from } 2004 \text { to } 2007 \text { of patients undergoing } \\
\text { primary PCI for STEMI. } N=28,936 \text {; } \\
10.8 \% \text { underwent multivessel PCI } \\
(n=3134) \text {. }\end{array}$ \\
\hline $\begin{array}{l}\text { Chen et al., } \\
2005 \text { [11] }\end{array}$ & $\begin{array}{l}\text { Retrospective analysis of patients presenting } \\
\text { with AMI (STEMI and NSTEMI) and } \\
\text { evidence of multivessel disease. } N=1384 \text {; } \\
\text { culprit-only PCI- } n=1189 \text {, multivessel PCI } \\
\text { undertaken within } 7 \text { days of AMI, } n=239 \text {. }\end{array}$ \\
\hline $\begin{array}{l}\text { Corpus et al. } \\
2004 .[12]\end{array}$ & $\begin{array}{l}\text { Retrospective analysis of } 506 \text { patients } \\
\text { presenting with STEMI and multivessel } \\
\text { disease, undergoing culprit-only PCI } \\
(n=354), \text { PCI of IRA+N-IRA during same } \\
\text { procedure }(n=26), \text { PCI of IRA and N-IRA } \\
\text { during index admission }(n=126) \text {. }\end{array}$ \\
\hline $\begin{array}{l}\text { Dziewierz } \\
\text { et al., } 2010 . \\
\text { [13] }\end{array}$ & $\begin{array}{l}\text { Retrospective analysis of } 1598 \text { STEMI } \\
\text { patients. } 777 \text { patients with MVD, } 70 \\
\text { underwent MV-PCI, } 707 \text { culprit-only. }\end{array}$ \\
\hline
\end{tabular}
underwent N-IRA PCI 7-15 days after PPCI to IRA.

Hannan et al., 2010 [15]

Khattab et al., 2007. [16]

Kornowski et al., 2011. [17]
Analysis of 668 STEMI patients from the HORIZONS-AMI trial, undergoing either same-setting MV-PCI $(n=275)$ or staged PCI $(n=373)$. NO difference in baseline
Staged PCI treatment

Pre-procedural cardiogenic shock, thrombolysis administered before PCI.

PCI to SVG, LMS, acute occlusion after angioplasty or staged OP procedure.

Cardiogenic shock, LMS, pulmonary oedema, LV rupture
As per HORIZONS-AMI trial: Prior thrombolysis, bivalirudin, GPI, LMWH,
Outcome measures.

Increased risk of in-hospital death: $5.45 \%$ vs $20.4 \%, P<0.05$; all-cause death: $10.9 \%$ vs $31.5 \%, P<0.05$ and MACE: $27.7 \%$ vs $46.2 \%, P<0.05$, in patients undergoing multivessel PCI.

Overall in-hospital mortality greater in patients with multivessel PCI (7.9\% vs. $5.1 \%, P<0.01)$. IN patients with STEMI and Cardiogenic shock, MV-PCI resulted in increased in-hospital mortality $(36.5 \%$ vs. $27.8 \%$ for culprit-only, adjusted $\mathrm{OR}=1.5,95 \% \mathrm{CI}=1.22-1.95$ )

No difference in 1-year survival (MV$\mathrm{PCI}=0.93,95 \% \mathrm{CI}=0.87-0.95$, culpritonly $\mathrm{PCI}=0.92,95 \% \mathrm{CI}=0.92-0.95$, $P=0.93$ ) or 1 year survival from MI and revascularisation $(\mathrm{MV}-\mathrm{PCI}=0.78,95 \%$ $\mathrm{CI}=0.73-0.84$, culprit-only $\mathrm{PCI}=0.78$, $95 \%$ CI $=0.75-0.81$ ).

MV-PCI associated with higher rate of reinfarction $(13.0 \% \mathrm{vs}, 2.8 \%, P<0.001)$, revascularisation ( $25 \%$ vs. $15 \%$, $P=0.007$ ) and MACE (40\% vs $28 \%$, $P=0.006$ ).

Higher rate of 30-day death, MI and revascularisation (adjusted $\mathrm{OR}=1.33$, $95 \% \mathrm{CI}=0.57=3.10, P=0.51)$, bleeding adjusted $(\mathrm{OR}=0.80,95 \% \mathrm{CI}=0.32-2.02$, $P=0.64$ ) and 1 year death (adjusted $\mathrm{OR}=2.04,95 \% \mathrm{CI}=0.89-4.66, P=0.09$ ). Not statistically significant.

No significant difference in 12-month MACE $(11.5 \%$ vs $15.1 \%, P>0.05)$ or target lesion revascularisation ( $8.1 \%$ vs $7.6 \%$, $P>0.05$ ). Higher rates of recurrent angina in IRA-only group $(10.1 \%$ vs $2.1 \%$, $P<0.05$ ).

Shock, previous heart surgery, LMS disease, thrombolysis

Non-significant trend towards higher inhospital, 12- and 42-month mortality in MV-PCI undertaken at time of index procedure compared with culprit-only PCI. Significant in-hospital mortality excess with index procedure MV-PCI compared to culprit-only PCI when haemodynamic instability excluded. Lower 12-month mortality with staged MV-PCI compared to culprit-only PCI (1.3\% vs $3.3 \%$, $P=0.04$ ).

Similar baseline characteristics. MACE (death, MI and TVR) at 12 months similar between the two treatment strategies (MVPCI $=24 \%$, culprit-only $=28 \%, P=0.73$ ). No difference in revascularisation (MVPCI $=24 \%$, culprit-only $\mathrm{PCI}=28 \%$, $P=0.73$ ).

Higher rates of 1-year mortality, cardiac mortality and definite/probable stent thrombosis in patients undergoing samesetting MV-PCI compared to staged PCI. 
Table 1 (continued)

\begin{tabular}{|c|c|c|c|}
\hline Study & Description & Exclusion criteria & Outcome measures. \\
\hline & $\begin{array}{l}\text { characteristics between groups, except } \\
\text { higher rates of TIMI0/1 flow in culprit } \\
\text { vessel in staged PCI group. }\end{array}$ & $\begin{array}{l}\text { warfarin, bleeding } \\
\text { diathesis, transfusion. }\end{array}$ & $\begin{array}{l}\text { Single-setting MV-PCI was independently } \\
\text { predictive of } 30 \text {-day and } 1 \text {-year mortality } \\
\text { and MACE (death, reinfarction, TVR and } \\
\text { stroke). }\end{array}$ \\
\hline $\begin{array}{l}\text { Lee et al., } 2012 \\
\quad[18]\end{array}$ & $\begin{array}{l}1644 \text { STEMI patients from Korean registry } \\
\text { with multivessel disease undergoing } \\
\text { culprit-only }(n=1106) \text { or multivessel PCI } \\
(n=538) \text {. Lower incidence of } 3 \mathrm{vD} \text { in } \\
\text { culprit-only group, higher number of } \\
\text { patients with EF }<40 \% \text { in culprit-only } \\
\text { group. }\end{array}$ & & $\begin{array}{l}\text { No significant difference in MACE (all-cause } \\
\text { death, MI, revascularisation, CABG) at } \\
30 \text { days or } 12 \text { months between the two } \\
\text { groups. Higher rate of TLR in MV-PCI } \\
\text { group ( } 2.4 \% \text { culprit-only, } 5.9 \% \text { MV-PCI, } \\
P<0.0001) \text {. }\end{array}$ \\
\hline $\begin{array}{l}\text { Manari et al. } \\
\text { 2014. [19] }\end{array}$ & $\begin{array}{l}2061 \text { STEMI patients with multivessel } \\
\text { disease undergoing PPCI; } 706 \text { culprit-only, } \\
367 \text { multivessel index procedure, } 988 \\
\text { staged PCI at } 60 \text { days. }\end{array}$ & $\begin{array}{l}\text { Shock, CTO in one vessel, } \\
\text { severe LMS, previous } \\
\text { CABG }\end{array}$ & $\begin{array}{l}\text { Multivariate analysis showed higher rates of } \\
\text { 30-day and 2-year mortality in culprit-only } \\
\text { PPCI compared to staged MV-PCI. Short- } \\
\text { term mortality rates higher for multivessel } \\
\text { PCI compared to culprit PPCI. }\end{array}$ \\
\hline $\begin{array}{l}\text { Quarani et al. } \\
\text { 2008. [20] }\end{array}$ & $\begin{array}{l}\text { Prospective non-randomised study of } 120 \\
\text { consecutive patient presenting with STEMI } \\
\text { and multivessel disease underwent either } \\
\text { culprit-only PCI }(n=25) \text { or complete } \\
\text { revascularisation }(n=95) \text {. }\end{array}$ & $\begin{array}{l}\text { Cardiogenic shock, LMS } \\
\quad>50 \% .\end{array}$ & $\begin{array}{l}\text { Reduction in in-hospital MACE events (in- } \\
\text { hospital mortality, recurrent ischaemia, } \\
\text { reinfarction, acute heart failure) with } \\
\text { complete revascularisation ( } 16.7 \% \text { vs } \\
52 \%, P=0.001) \text {, driven by reductions in } \\
\text { recurrent ischaemia, reinfarction and acute } \\
\text { heart failure. Increased CIN seen in MV- } \\
\text { PCI group. }\end{array}$ \\
\hline $\begin{array}{l}\text { Rigattieri et al., } \\
\text { 2007. [21]. }\end{array}$ & $\begin{array}{l}\text { Retrospective comparison of STEMI patients } \\
\text { with multivessel PCI undergoing culprit- } \\
\text { only }(n=46) \text { or early, staged N-IRA PCI } \\
(n=64) \text {. }\end{array}$ & $\begin{array}{l}\text { Cardiogenic shock, LMS } \\
\text { disease, severe valvular } \\
\text { disease, previous CABG. }\end{array}$ & $\begin{array}{l}\text { Non-significantly Higher in-hospital MACE } \\
\text { with complete revascularisation }(20.3 \% \\
\text { vs. } 10.8 \%, P=0.186) \text {, driven by } \\
\text { periprocedural MI. Lower follow-up } \\
\text { MACE events with staged MV-PCI. }\end{array}$ \\
\hline $\begin{array}{l}\text { Roe et al., } \\
\text { 2001. [22]. }\end{array}$ & $\begin{array}{l}\text { Retrospective study of } 68 \text { cases of multivessel } \\
\text { PCI at time of IRA-primary PCI, matched } \\
\text { to } 61 \text { cases of primary PCI IRA-only PCI. }\end{array}$ & & $\begin{array}{l}\text { IN the primary PCI subgroup analysis: } \\
\text { MACE higher in MV-PCI ( } 35.3 \% \text { vs. } \\
27.9 \%, P=0.63 \text { ). Significantly higher risk } \\
\text { of stroke with MV-PCI ( } 10.3 \% \text { vs } 0 \% \text {, } \\
P=0.01 \text { ) and non-significantly increase } 6 \text { - } \\
\text { month mortality and reinfarction. }\end{array}$ \\
\hline $\begin{array}{l}\text { Toma et al. } \\
2010 \text { [23]. }\end{array}$ & $\begin{array}{l}\text { Retrospective analysis of } 2201 \text { STEMI } \\
\text { patients with MVD in the APEX-AMI trial; } \\
217 \text { underwent N-IRA PCI, } 1984 \\
\text { underwent IRA-PCI alone. }\end{array}$ & & $\begin{array}{l}\text { 90-day death rate significantly higher in N- } \\
\text { IRA PCI group }(12.5 \% \mathrm{~N} \text {-IRA; } 5.6 \% \\
\text { IRA-only, } P(\log \text { rank })<0.001) .90 \text {-day } \\
\text { composite of } 90 \text {-day death, CHF and shock } \\
\text { from randomisation higher in N-IRA PCI } \\
\text { group. }\end{array}$ \\
\hline $\begin{array}{l}\text { Varani et al., } \\
\text { 2008. [24]. }\end{array}$ & $\begin{array}{l}\text { Retrospective study of } 399 \text { patients with } \\
\text { STEMI and MVD (IRA-only=156, MV- } \\
\text { PCI at index procedure }=147, \text { MV-PCI } \\
\text { staged pre discharge }=96 \text { ) }\end{array}$ & & $\begin{array}{l}\text { After exclusion of patients with cardiogenic } \\
\text { shock and pulmonary oedema (seen more } \\
\text { often in index procedure MV-PCI); MV- } \\
\text { PCI } 30 \text { day mortality }=2.8 \% \text {, IRA- } \\
\text { only }=6.3 \% \text {. Rate of MV-PCI similar to } \\
\text { STEMI patients with single-vessel disease } \\
\text { in this cohort. No difference in } 30 \text {-day } \\
\text { mortality between single-setting and staged } \\
\text { procedure for N-IRA lesion }\end{array}$ \\
\hline
\end{tabular}

Abbreviations: $M V-P C I$ multivessel percutaneous coronary intervention, $M A C E$ major adverse cardiovascular events (as defined in each study), $L M S$ left main stem, IRA infarct-related artery, $N$-IRA non-infarct-related artery, $M I$ myocardial infarction, STEMI ST elevation myocardial infarction, CTO chronic total occlusion, $S V G$ saphenous vein graft, $M V D$ multivessel disease

revascularisation $(\mathrm{HR}=0.35,95 \% \mathrm{CI}=0.21-0.58, P<0.001)$ having been reached. In particular, this appeared to be driven primarily by a significant reduction in refractory angina $(\mathrm{HR}=$ $0.35,95 \% \mathrm{CI}=0.13-0.75)$ and non-fatal myocardial infarction $(\mathrm{HR}=0.32,95 \% \mathrm{CI}=0.13-0.75)$, although no significant reduction in mortality was shown. The randomisation process was not stratified for timing of intervention in relation to symptom onset, nor for site of infarction. Indeed, the 
infarct-related artery (IRA)-only group in this study demonstrated a higher proportion of diabetic patients and those admitted with anterior MI, both known to confer worse prognosis following acute myocardial infarction.

CvLPRIT was a second open randomised trial comparing culprit lesion only with complete intervention in patients presenting with STEMI and evidence of multivessel disease $[30 \bullet \cdot$. N-IRA lesions were defined as those being $>70 \%$ diameter stenosis. A total of 296 patients were recruited to the study over a similar timeframe as PRAMI. Patients were randomised to either complete or culprit-only revascularisation following confirmation on index angiography of one or more N-IRA lesions. In this study, the N-IRA PCI could be undertaken either at the time of index primary PCI to the culprit, or on a separate occasion but within the same admission. Like PRAMI, this trial showed a reduction in the primary endpoint of death, MI, heart failure and ischaemic-driven revascularisation with complete revascularisation $(\mathrm{HR}=0.45,95 \% \mathrm{CI}=0.24-0.84, P=$ 0.009). Within the components of the primary endpoint, while showing a trend towards lower adverse events with complete revascularisation, none of the individual components of the primary endpoint attained statistical significance. In addition, there was a very early separation of the Kaplan-Meier event curves between the two randomised groups, suggesting an early benefit with complete revascularisation. As with PRAMI, the trial had small number of events in both arms, and the open-label nature of the study may have an impact on revascularisation in patients with known untreated N-IRA lesions in the culprit-only group.

Subsequent important contributions to the evidence base include the Third DANish Study of Optimal Acute Treatment of Patients with ST-segment Elevation Myocardial Infarction. The PRImary PCI in MULTIvessel Disease (DANAMI3-PRIMULTI) trial [31] recently reported and was a randomised trial recruiting 627 patients from a cohort of 2239 patients who had initially been randomised to the "ischaemic post-conditioning (iPOST)" or "deferred stenting (DEFER)" other arms of the study, and in whom there was evidence of multivessel disease with successful primary PCI of the IRA. The patients were then randomised to receive either fractional flow reserve (FFR)-guided intervention of N-IRA lesions, or medical management with no further intervention. The primary endpoint was composite of all-cause mortality, non-fatal myocardial infarction and ischaemic-driven revascularisation of N-IRA lesions. As with CVLPRIT and PRAMI, this study also showed benefit in favour of complete revascularisation ( $\mathrm{HR}=0.56$, $95 \% \mathrm{CI}=0.38-0.83, P=0.004)$; however, there was no significant difference in all-cause mortality nor in non-fatal myocardial infarction between the two groups the reduction in composite endpoint being primarily driven by a reduced rate of ischaemic-driven revascularisation in the FFR- guided complete revascularisation group ( $\mathrm{HR}=0.31,95 \%$ $\mathrm{CI}=0.18-0.53, P<0.001)$.

PRAGUE-13 randomised 214 STEMI patients with multivessel disease to either complete revascularisation between 3 and 40 days post PPCI or IRA-PCI only [32]. This trial demonstrated no difference in MACE (death/MI/CVA) between the two groups ( $\mathrm{HR}=1.36,95 \% \mathrm{CI}=0.66-2.74)$. However, the severity of N-IRA lesions was less than in other studies, with only $6.1 \%$ of N-IRA lesions being classed as $>95 \%$ stenosis. This study did not include ischaemia-driven revascularisation as part of the endpoint and was underpowered to detect differences in hard endpoints. It is generally regarded as a trial of less significant non-IRA lesions.

In 2014, PRAMI and CvLPRIT led to the ACC withdrawing a "do-not-do" recommendation of complete revascularisation in STEMI patients with multivessel disease. The results of these trials and associate meta-analyses suggest that the current guideline recommendations pertaining to management of multivessel disease in STEMI should be revisited.

\section{Safety of Complete Revascularisation}

Performing complete revascularisation has been shown to result in greater use of contrast, prolonged procedural time and increased exposure to radiation especially when performed at the same time as the index primary PCI for the culprit lesion $[29 \bullet \bullet, 30 \bullet, 31,33]$. In spite of this, a pooled analysis of PRAMI, CvLPRIT and the trial by Politi et al. has shown no increase in CVA, bleeding or contrast-induced nephropathy [34•]. Thus, the data suggest, although procedure times and contrast use may be increased with complete revascularisation, this does not translate to an increased risk of adverse events. Similarly, there was no difference in rates of periprocedural MI, stroke, contrast-induced nephropathy or bleeding between the two revascularisation strategies in the DANAMI3-PRIMULTI study [31].

\section{Is There a Prognostic Benefit for Complete Revascularisation?}

Although the recent RCTs demonstrate a benefit of composite MACE endpoints with complete revascularisation, in CVLPRIT and DANAMI3-PRIMULTI, this has mainly been driven by a reduction in ischaemia-driven revascularisation within the complete revascularisation arm. In PRAMI, a reduction in refractory angina and non-fatal myocardial infarction was seen; however, ischaemia-driven revascularisation (in this study as a secondary endpoint) was also reduced. However, none of these trials were adequately powered to detect a difference in prognostic clinical endpoints of death or myocardial infarction. 
A meta-analysis of four RCTs that compared culprit-only and complete revascularisation (CVLPRIT, PRAMI, Politi and HELP-AMI) consisting of 1044 randomised patients demonstrated significant reduction in long-term $(\geq 1$ year) all-cause mortality (RR: $0.57,95 \% \mathrm{CI}=0.36-0.92, P=0.02$ ), cardiovascular death (RR: $0.38,95 \% \mathrm{CI}=0.20-0.73, P=0.004)$ and myocardial infarction (RR: $0.41,95 \% \mathrm{CI}=0.23-0.75 ; P=$ 0.004 ) with complete revascularisation compared to culpritonly PCI. In all three analyses, there was a low degree of heterogeneity between the included studies [34 $]$. There was a low degree of heterogeneity between the included studies ( $I^{2}=0 \%$ for all three outcome measure comparisons).

Similarly, meta-analyses described below including both randomised trials and non-randomised studies have demonstrated a reduction in long-term mortality rates when complete revascularisation is performed as a staged procedure (i.e. not at the index primary PCI procedure) $[25 \bullet, 35]$.

While the above meta-analyses indicate a signal towards improved death and MI with complete revascularisation, they are limited by the design limitations of the individual studies and also the heterogeneity between the studies in terms of inclusion and exclusion criteria, timing of the N-IRA procedures and outcome measures. Hence, this question can only be answered robustly by appropriately powered randomised trials with sufficient numbers to detect any differences in death and MI between strategies.

\section{Timing of Complete Revascularisation}

An issue not fully addressed by the recent randomised trials is the optimal timing of complete revascularisation. Mechanistically, performing complete revascularisation at the time of culprit primary PCI could potentially lead to extension of infarcted muscle if the attempted PCI to the N-IRA were to be complicated by coronary dissection or stent thrombosis, socalled double jeopardy.

Potential timing for complete revascularisation include undertaking it at the time of index primary PCI, as a separate procedure during the index admission, or as a planned elective outpatient procedure for the N-IRA lesions.

Hannan et al. (2010) published registry data of multivessel disease in STEMI undergoing primary PCI between Jan 2003 and June 2006 [15]. A total of 3521 patients were included, of whom 259 underwent staged PCI during the index admission, and 538 underwent staged intervention of N-IRA lesions within 60 days of discharge from index admission. Patients with shock, previous heart surgery, LMS disease or thrombolysis prior to PCI were excluded. Propensity matching was undertaken for comparison of inpatient, mortality between culpritonly PCI, complete revascularisation during index procedure and staged complete revascularisation as defined above.
This study showed in patients without features of haemodynamic instability, increased in-hospital mortality occurred with complete revascularisation at index procedure compared to culprit-only (complete revascularisation at time of index PCI $=2.4 \%$, culprit-only $\mathrm{PCI}=0.9 \%, P=0.04$ ).

There was however a difference in 12-month mortality in favour of complete revascularisation when undertaken as a staged procedure within 60 days compared to culprit-only PCI (staged complete revascularisation $=1.3 \%$, culprit-only $\mathrm{PCI}=3.3 \%, P=0.04)$. Overall, the findings from this registry data indicate that a potential mortality benefit was present if N-IRA PCI was performed as a staged procedure and also suggested potentially worse outcomes by complete revascularisation at the time of the index procedure.

A meta-analysis of randomised and non-randomised studies [25•] suggests that index procedure complete revascularisation may be associated with increased inhospital morality, while performing staged complete revascularisation was associated with reduced in-hospital mortality (OR 0.35, $95 \% \mathrm{CI}=0.21-0.59 ; P<.001 ; P$ interaction $<.001)$. The same meta-analysis also showed reduced longer-term mortality with complete revascularisation (OR $0.74,95 \% \mathrm{CI}=0.65-0.85, P<.001)$ and repeat PCI (OR $0.65 ; 95 \% \mathrm{CI}=0.46-0.90, P=.01$ [randomised OR 0.31 , $95 \% \mathrm{CI}=0.17-0.57, P<.001$; non-randomised OR 0.88 , $95 \% \mathrm{CI}=0.59-1.31, P=.54])$.

A paired and network meta-analysis of 14 studies including 40,280 patients, compared three timing strategies in STEMI patients with multivessel disease; staged PCI, (defined in this analysis as separate procedure either during index admission or within 1 month of the primary PCI), complete revascularisation during index primary PCI procedure, and culprit-only PCI. This analysis showed lowest short- and long-term mortality rates in patients undergoing staged complete revascularisation [35]. The majority of the studies within this analysis were retrospective cohort studies, and although in some cardiogenic shock were excluded, given that for retrospective studies the decision to perform either index procedure or staged complete revascularisation was not prospectively registered, the analysis could not fully adjust for any important patient characteristics that may have influenced the decision for index procedure complete revascularisation.

While the above studies suggest deferring N-IRA PCI to a staged procedure, data from the randomised studies with regard to timing of the intervention do not support this strategy. The Politi study [33] randomised patients to receive either inpatient, staged outpatient complete revascularisation or culprit-only revascularisation. This showed lower rates of MACE with complete revascularisation compared to culpritonly; however, there appeared to be no difference in MACE event rates between inpatient and staged outpatient complete revascularisation. 
The CvLPRIT study suggested that there may be benefit from early intervention, with a landmark analysis of the data at 30 days showing a trend towards improved early MACE reduction with complete revascularisation $(\mathrm{HR}=0.45,95 \%$ $\mathrm{CI}=0.19-1.04, P=0.055)$. Although this did not achieve statistical significance, there is a clear early separation in the Kaplan-Meier curves for MACE. A subsequent analysis of the 139 patients who underwent complete revascularisation within the study showed no difference in the 12-month primary composite MACE endpoint (death/MI/HF/repeat revascularisation) between complete revascularisation at the index procedure compared with staged inpatient revascularisation $(6.2 \%$ index complete vs. $11.9 \%$ staged inpatient; $\mathrm{HR}=0.51,95 \% \mathrm{CI}=0.16-1.67, P=0.29)$. Although when looking at composite of death/MI/HF, there was a nonsignificant trend towards lower rates with index procedure complete revascularisation $(3.1$ vs. $11.9 \%$; $\mathrm{HR}=0.26,95 \%$ $\mathrm{CI}=0.06-1.08, P=0.06$ ). These post-hoc analysis results have to be interpreted with caution as the patients were not randomised to performing either index procedure or staged inpatient complete revascularisation. .

Comparison of index procedure and staged outpatient complete revascularisation was also examined in a randomised trial by Ochala et al. [36]. In this study, 98 patients were randomised to receive either one-stage (index procedure) or two-stage (elective outpatient) complete revascularisation. Cardiogenic shock and LMS $>50 \%$ were excluded from the study. There was no difference in MACE (defined as all-cause death, MI, urgent revascularisation) or improvement in LVEF between the 2 groups, with staged revascularisation of N-IRA lesions performed $27.3 \pm 12.8$ days after primary PCI.

When N-IRA PCI should be performed remains an issue for further research in adequately powered studies.

\section{Assessing the Significance of Non-culprit Lesions: Functional vs. Anatomical vs. Plaque Composition}

Most of the observational and randomised studies have used angiographic diameter stenosis severity to determine N-IRA lesions requiring treatment. However, it is known within the context of stable angina assessment that determining the haemodynamic significance of lesions using fractional flow reserve may allow for more accurate identification of lesions requiring intervention.

Ntaliansis et al. showed that amongst 75 STEMI patients, there was no significant change in the FFR measurement in the non-IRA when repeated at a mean of $35 \pm 4$ days post initial procedure $(0.78 \pm 0.10$ vs. $0.76 \pm 0.10, P=\mathrm{NS})$ [37].

Preliminary data from the COMPARE-ACUTE study also suggest a disparity between angiographic-determined significance and haemodynamically significant N-IRA lesions in STEMI patients. In 408 STEMI patients with evidence of multivessel disease defined by presence of N-IRA lesions with diameter stenosis of $>50 \%$, FFR measurements performed at the time of index procedure showed that in $56.5 \%$ the FFR was negative $(<0.8)$ [38].

Dambrink et al. randomised 121 STEMI patients with multivessel disease (N-IRA lesions of $>50 \%$ diameter stenosis) in a 2:1 fashion to receive either early FFR-guided revascularisation of N-IRA lesions or to conservative medical treatment [39]. Randomisation occurred following successful primary PCI of the culprit lesion. Repeat angiography in the invasive group was performed at a median of 7.5 days after primary PCI.

Of the 80 patients allocated to the invasive treatment arm, only 65 underwent FFR assessment of non-culprit lesions. From these, 42 patients (50 lesions) demonstrated positive FFR measurement, with 23 patients (41 lesions) with negative FFR and hence managed conservatively.

At 6 months, there was no difference in MACE rates (death/MI/repeat PCI) between the two strategies using an intention-to-treat analysis ( 16 vs. $22 \%, P=0.292$ ). A prespecified per protocol analysis showed significantly higher rates of repeat PCI in the culprit-only group ( 6 vs. $22 \%, P=$ 0.017), with death and MI occurring solely in the FFR-guided revascularisation group, leading to comparable 6-month composite MACE rates ( 14 vs. $22 \%, P=0.292$ ). A longer-term follow-up to 3 years of these patients showed no significant difference in all-cause mortality between invasive and conservatively managed groups, higher rate of death and non-fatal MI with the invasively treated group $(13.4 \%$ all in the invasive group, $P=0.002$ ); however, lower rate of $\mathrm{PCI}$ in nonculprit vessel in the invasive group ( 8.9 vs. $32.5 \%, P=$ $0.001)$. There was no difference in MACE between the two groups ( 35 vs. $35 \%, P=0.896$ ) [40]; however, the study was not powered to detect difference in MACE.

DANAMI3-PRIMULTI also employed FFR as a means of selecting N-IRA lesions for intervention. There was a significant reduction in MACE event rates with complete revascularisation, driven mainly by a reduction in ischaemiadriven revascularisation in the complete revascularisation arm [31]. However, no assessment was made of the haemodynamic significance of N-IRA lesions in the medically managed group.

None of the above studies addresses the question of whether FFR provides a more sensitive means of determining which N-IRA lesions should be intervened upon compared to assessment by angiographic significance. The COMPARE-ACUTE trial (NCT01399736) is currently ongoing and will recruit 885 patients, comparing FFR-guided complete revascularisation with culprit-only PCI. This study will also compare MACE outcomes as one of the subgroup analyses staged PCI to N-IRA lesions that are angiographically significant (DS $>50 \%$ ) but with a negative FFR with not intervening on these lesions. 
While clearly there is evidence to support use of FFR in determining significant flow-limiting lesions in stable angina, one aspect with regard to N-IRA lesions in STEMI is that they may represent a more vulnerable plaque morphology compared to stable angina patients, and hence outcomes may not solely be driven by the haemodynamic significance of the lesion. Analysis non-culprit lesions of ACS patients using VH-IVUS has shown a greater proportion of vulnerable plaques, with greater proportion of necrotic core and thincap fibroatheroma compared with stable coronary lesions [41]. TCFA lesions were also seen in $46.7 \%$ of non-culprit lesions within ACS population from the PROSPECT study; logistic regression demonstrated the presence of TCFA at nonculprit site was an independent predictor of future MACE events [42].

Similarly, Kato et al. [43•] have demonstrated differences in plaque composition in non-culprit lesions from ACS patients compared to stable angina plaques using three-vessel OCT. Specifically, non-culprit plaques demonstrated wider lipid arc $\left(147.3 \pm 29.5^{\circ}\right.$ versus $\left.116.2 \pm 33.7^{\circ}, P<0.001\right)$, a longer lipid length $(10.7 \pm 5.9$ versus $7.0 \pm 3.7 \mathrm{~mm}, P=0.002)$, a larger lipid volume index [averaged lipid arc $\times$ lipid length] $(1605.5 \pm 1013.1$ versus $853.4 \pm 570.8, P<0.001)$ and a thinner fibrous cap $(70.2 \pm 20.2$ versus $103.3 \pm 46.8 \mu \mathrm{m}, P<0.001)$. Also, there was a higher prevalence of TCFA in non-culprit ACS lesions compared to stable angina patients. These findings suggest that non-culprit plaques in ACS patients are inherently more vulnerable and may account for recurrent ischaemic events occurring after the primary event at these sites.

Hence, one could hypothesise that in the context of STEMI and multivessel disease, plaque morphology in addition to haemodynamic significance, should drive decision making in terms of N-IRA PCI. Further studies using VH-IVUS or OCT to determine plaque composition in N-IRA lesions and impact of this on preventing future MACE events, particularly hard endpoint of non-fatal MI, would be required. Findings from intracoronary near infra-red spectroscopy have identified plaques with large lipid cores at culprit sites for STEMI and NSTEMI $[44,45]$. This may also provide a useful tool for sitespecific identification of N-IRA plaques that may give rise to future coronary events; however, this hypothesis would also require validation in large prospective randomised studies.

\section{Conclusions}

The recently reported PRAMI, CVLPRIT and DANAMI3PRIMULTI randomised controlled trials have shown that in patients presenting with STEMI and evidence of additional non-infarct-related artery lesions, a strategy of complete revascularisation results appears to result in improved clinical outcomes compared with culprit-only PCI. These studies shed new light on the management of such patients, as previous studies were non-randomised and retrospective in nature. In addition, these RCTs reflect more contemporary clinical practice with regard to use of drug-eluting stents, radial access as the preferred vascular approach and use of newer generation $\mathrm{P}_{2} \mathrm{Y}_{12}$ inhibitors such as Prasugrel and Ticagrelor, all of which may add towards the improved clinical outcomes seen compared to previous trials.

There however remain unanswered questions with regard to the optimal management strategy of STEMI patients with multivessel disease. The timing of intervention in N-IRA arteries remains unclear, with current data presenting conflicting evidence in terms of whether same sitting, same admission or staged procedures would result in improved outcomes. Another issue is the optimal method of determining which N-IRA lesions require intervention, either by angiographic severity or use of FFR to guide intervention based on haemodynamic significance of N-IRA lesions.

Finally, although the recently reported RCTs demonstrate improved MACE outcomes with complete revascularisation, these are mostly driven by ischaemic-driven revascularisation and MI in the case of PRAMI. Hence, larger studies powered to detect differences in hard clinical endpoints of death and MI are required.

\section{Compliance with Ethics Guidelines}

Conflict of Interest Amerjeet S. Banning and Anthony H. Gershlick declare that they have no conflict of interest.

Human and Animal Rights and Informed Consent This article does not contain any studies with human or animal subjects performed by any of the authors.

Open Access This article is distributed under the terms of the Creative Commons Attribution 4.0 International License (http:// creativecommons.org/licenses/by/4.0/), which permits unrestricted use, distribution, and reproduction in any medium, provided you give appropriate credit to the original author(s) and the source, provide a link to the Creative Commons license, and indicate if changes were made.

\section{References}

Papers of particular interest, published recently, have been highlighted as:

- Of importance

•. Of major importance

1. Kahn JK, Rutherford BD, McConahay DR, et al. Results of primary angioplasty for acute myocardial infarction in patients with multivessel coronary artery disease. J Am Coll Cardiol. 1990;16: 1089-96.

2. Goldstein JA, Demetriou D, Grines CL, Pica M, Shoukfeh M, O'Neill WW. Multiple complex coronary plaques in patients with acute myocardial infarction. N Engl J Med. 2000;343:915-22. 
3. Jaski BE, Cohen JD, Trausch J, et al. Outcome of urgent percutaneous transluminal coronary angioplasty in acute myocardial infarction: comparison of single-vessel versus multivessel coronary artery disease. Am Heart J. 1992;124:1427-33.

4. Califf RM, Topol EJ, Stack RS, et al. Evaluation of combination thrombolytic therapy and timing of cardiac catheterization in acute myocardial infarction. Results of thrombolysis and angioplasty in myocardial infarction-phase 5 randomized trial. TAMI study group. Circulation. 1991;83:1543-56.

5. Lee JH, Park HS, Chae SC, et al. From the Korea acute myocardial infarction registry. predictors of six-month major adverse cardiac events in 30-day survivors after acute myocardial infarction. Am J Cardiol. 2009;104:182-9.

6. Sorajja P, Gersh BJ, Cox BA, et al. Impact of multivessel disease on reperfusion success and clinical outcomes in patients undergoing primary percutaneous coronary intervention for acute myocardial infarction. Eur Heart J. 2007;28:1709-16.

7. O'Gara PT, Kushner FG, Ascheim DD, et al. 2013 ACCF/AHA guideline for the management of ST-elevation myocardial infarction: a report of the american college of cardiology foundation/ american heart association task force on practice guidelines. J Am Coll Cardiol. 2013;61:e78-140.

8. Steg PG, James SK, Atar D, et al. ESC Guidelines for the management of acute myocardial infarction in patients presenting with STsegment elevation. Eur Heart J. 2012;33:2569-619.

9. Abe D, Sato A, Hoshi T, et al. Initial culprit-only versus initial multivessel percutaneous coronary intervention in patients with ST-segment elevation myocardial infarction: results from the Ibaraki cardiovascular assessment study registry. Heart Vessels. 2014;29:171-7.

10. Cavender MA, Milford-Beland S, Roe MT, et al. Prevalence, predictors, and in-hospital outcomes of Non-infarct artery intervention during primary percutaneous coronary intervention for ST-segment elevation myocardial infarction (from the national cardiovascular data registry). Am J Cardiol. 2009;104:507-13.

11. Chen LY, Lennon RJ, Grantham JA, et al. In-hospital and long-term outcomes of multivessel percutaneous coronary revascularization after acute myocardial infarction. Am J Cardiol. 2005;95:349-54.

12. Corpus RA, House JA, Marso SP, et al. Multivessel percutaneous coronary intervention in patients with multivessel disease and acute myocardial infarction. Am Heart J. 2004;148:493-500.

13. Dziewierz A, Siudak Z, Rakowski T, et al. Impact of multivessel coronary artery disease and noninfarct-related artery revascularization on outcome of patients with ST-elevation myocardial infarction transferred for primary percutaneous coronary intervention (from the EUROTRANSFER registry). Am J Cardiol. 2010;106:342-7.

14. Han Y, Wang B, Wang X, et al. Comparative effects of percutaneous coronary intervention for infarct-related artery only or for both infarct- and non-infarct related arteries in patients with ST-elevation myocardial infarction and multi-vessel disease. Chin Med J. 2008;121(23):2384-7.

15. Hannan EL, Samadashvili Z, Walford G, et al. Culprit vessel percutaneous coronary intervention versus multivessel and staged percutaneous coronary intervention for ST-segment elevation myocardial infarction patients with multivessel disease. J Am Coll Cardiol Intv. 2010;3:22-31.

16. Khattab AA, Abdel-Wahab M, Rother C, et al. Multi-vessel stenting during primary percutaneous coronary intervention for acute myocardial infarction: a single-center experience. Clin Res Cardiol. 2008;97:32-8.

17. Kornowski R, Mehran R, Dangas G, et al. Prognostic impact of staged versus "One-time" multivessel percutaneous intervention in acute myocardial infarction: analysis from the HORIZONS-AMI (harmonizing outcomes with revascularization and stents in acute myocardial infarction) trial. J Am Coll Cardiol. 2011;58:704-11.
18. Lee HW, Hong TJ, Yang MJ, et al. Comparison of infarct-related artery vs multivessel revascularization in ST-segment elevation myocardial infarction with multivessel disease: analysis from Korea acute myocardial infarction registry. Cardiol J. 2012;19(3): 256-66.

19. Manari A, Varani E, Guastarbora P, et al. Long-term outcome in patients with ST segment elevation myocardial infarction and multivessel disease treated with culprit-only, immediate, or staged multivessel percutaneous revascularization strategies: insights from the REAL registry. Catheter Cardiovasc Interv. 2014;84:912-22.

20. Qarawani D, Nahir M, Abboud M, et al. Culprit only versus complete coronary revascularization during primary PCI. Int J Cardiol. 2008;123:288-92.

21. Rigattieri S, Biondi-Zoccai G, Silvestri P, et al. Management of multivessel coronary disease after ST elevation myocardial infarction treated by primary angioplasty. J Interv Cardiol. 2008;21:1-7.

22. Roe MT, Cura FA, Joski PS, et al. Initial experience with multivessel percutaneous coronary intervention during mechanical reperfusion for acute myocardial infarction. Am J Cardiol. 2001;88:170-3.

23. Toma M, Buller CE, Westerhout CM, et al. Non-culprit coronary artery percutaneous coronary intervention during acute ST-segment elevation myocardial infarction: insights from the APEX-AMI trial. Eur Heart J. 2010;31:1701-7.

24. Varani E, Balducelli M, Aquilina M, et al. Single or multivessel percutaneous coronary intervention in ST-elevation myocardial infarction patients. Catheter Cardiovasc Interv. 2008;72:927-33.

25. Bainey KR, Mehta SR, Lai T, Welsh RC. Complete vs culprit-only revascularization for patients with multivessel disease undergoing primary percutaneous coronary intervention for ST-segment elevation myocardial infarction: a systematic review and meta-analysis. Am Heart J. 2014;167:1-14. This meta-analysis of randomised and non-randomised studies suggest a longer-term mortality benefit from complete revascularisation, when undertaken as a staged procedure.

26. Bangalore S, Kumar S, Poddar KL, Ramasamy S, Rha S-W, Faxon DP. Meta-analysis of multivessel coronary artery revascularization versus culprit-only revascularization in patients with ST-segment elevation myocardial infarction and multivessel disease. Am J Cardiol. 2011;107:1300-10.

27. Iqbal MB, Ilsley C, Kabir T, et al. Culprit vessel versus multivessel intervention at the time of primary percutaneous coronary intervention in patients with ST-segment-elevation myocardial infarction and multivessel disease: real-world analysis of 3984 patients in London. Circ Cardiovasc Qual Outcomes. 2014;7:936-43.

28. Park D, Clare RM, Schulte PJ, et al. Extent, location, and clinical significance of Non-infarct-related coronary artery disease among patients with ST-elevation myocardial infarction. JAMA. 2014;312(19):2019-27.

29.• Wald DS, Morris JK, Wald NJ, et al. Randomized trial of preventive angioplasty in myocardial infarction. N Engl J Med. 2013;369: 1115-23. Randomised study of complete (preventive) vs. culprit-only (non-preventive) PCI in patients with STEMI and multivessel disease. Reduction in composite endpoint (death, MI, and refractory angina) seen with complete revascularisation, driven by reductions in refractory angina and non-fatal MI.

30.• Gershlick AH, Khan JN, Kelly DJ, et al. Randomized trial of complete versus lesion-only revascularization in patients undergoing primary percutaneous coronary intervention for STEMI and multivessel disease: the CvLPRIT trial. J Am Coll Cardiol. 2015;65(10):963-72. Randomised study comparing complete with culprit-only revascularisation, demonstrating lower MACE events with complete revascularisation. The study also suggests a benefit from early (in-patient) complete revascularisation may be seen. 
31. Engstrøm T. The third DANish study of optimal acute treatment of patients with ST-segment elevation myocardial infarction: PRImary PCI in MULTIvessel disease. Presented at: American College of Cardiology/i2 Scientific Session; March 16, 2015; San Diego, CA.

32. Hlinomaz O. Multivessel coronary disease diagnosed at the time of primary PCI for STEMI: complete revascularization versus conservative strategy: the PRAGUE 13 trial. Presented at: EuroPCR; May 19, 2015; Paris, France.

33. Politi L, Sgura F, Rossi R, et al. A randomised trial of target-vessel versus multi-vessel revascularisation in ST-elevation myocardial infarction: major adverse cardiac events during long-term followup. Heart. 2010;96:662-7.

34. El-Hayek GE, Gershlick AH, Hong MK, et al. Meta-analysis of randomized controlled trials comparing multivessel versus culpritonly revascularization for patients with ST-segment elevation myocardial infarction and multivessel disease undergoing primary percutaneous coronary intervention. Am J Cardiol. 2015;115(11): 1481-6. Meta-analysis of 4 randomised controlled trials, including PRAMI and CvLPRIT, indicating reduction in MACE events and reduction in $M I$ and mortality as well as revascularisation with complete revascularisation.

35. Vlaar PJ, Mahmoud KD, Holmes DR, et al. Culprit vessel only versus multivessel and staged percutaneous coronary intervention for multivessel disease in patients presenting with ST-segment elevation myocardial infarction: a pairwise and network meta-analysis. J Am Coll Cardiol. 2011;58:692-703.

36. Ochala A, Smolka GA, Wojakowski W, et al. The function of the left ventricle after complete multivessel one-stage percutaneous coronary intervention in patients with acute myocardial infarction. J Invasive Cardiol. 2004;16:699-702.

37. Ntalianis A, Sels JW, Davidavicius G, et al. Fractional flow reserve for the assessment of non-culprit coronary artery stenoses in patients with acute myocardial infarction. JACC Cardiovasc Interv. 2010;3:1274-81.
38. Smits PC, Vlachojannis GJ, Lunde K et al. TCT-328 FFR-guided complete revascularization during primary PCI: preliminary data from the COMPARE ACUTE trial. J Am Coll Cardiol. 2014; 64(11_S): doi:10.1016/j.jacc.2014.07.374.

39. Dambrink JE, Dedrauwere JP, van't Hof AWJ, et al. Non-culprit lesions detected during primary PCI: treat invasively or follow the guidelines? EuroIntervention. 2010;5(8):968-75.

40. Ghani A, Dambrink JH, van 't Hof AW, et al. Treatment of nonculprit lesions detected during primary PCI: long-term follow-up of a randomised clinical trial. Neth Heart J. 2012;20(9):347-53.

41. Hong YJ, Jeong MH, Choi YH, et al. Comparison of coronary plaque components between Non-culprit lesions in patients with acute coronary syndrome and target lesions in patients with stable angina: virtual histology-intravascular ultrasound analysis. Korean Circ J. 2013;43(9):607-14.

42. Stone GW, Maehara A, Lansky AJ, et al. A prospective naturalhistory study of coronary atherosclerosis. N Engl J Med. 2011;364(3):226-35.

43. Kato K, Yonetsu T, Kim S, et al. Nonculprit plaques in patients with acute coronary syndromes have more vulnerable features compared with those with Non-acute coronary syndromes: a 3-vessel optical coherence tomography study. Circ Cardiovasc Imaging. 2012;5: 433-40. This study indicates that non-culprit lesions in ACS patients may be morphologically different from plaques for stable angina, with more features in keeping with vulnerable plaques. Hence, this may indicate N-IRA lesions should be considered differently from stable plaques.

44. Madder RD, Goldstein JA, Madden SP, et al. Detection by nearinfrared spectroscopy of large lipid core plaques at culprit sites in patients with acute ST-segment elevation myocardial infarction. JACC Cardiovasc Interv. 2013;6(8):838-46.

45. Madder RD, Husaini M, Davis AT, et al. Detection by near-infrared spectroscopy of large lipid cores at culprit sites in patients with nonst-segment elevation myocardial infarction and unstable angina. Catheter Cardiovasc Interv. 2014. doi:10.1002/ccd.25754. 